\title{
Blended Learning in Linear Algebra
}

\author{
Yanita $^{1}$, Nova Noliza Bakar ${ }^{2}$ \\ \{yanita@sci.unand.ac.id ${ }^{1}$, kieknova@gmail.com ${ }^{2}$ \} \\ ${ }^{1,2}$ Department of Mathematic, Faculty of Mathematics and Natural Science, Universitas Andalas, \\ Padang, Indonesia
}

\begin{abstract}
This paper discusses the learning process of Linear algebra courses using blended learning. Given the design and practicality of blended learning for this course based on the author's experience teaching Linear Algebra. The purpose of this design is to increase students' understanding in learning Linear Algebra by using the blended learning method.
\end{abstract}

Keywords: blended learning, linear algebra.

\section{Introduction}

Blended learning is the thoughtful fusion of face-to-face and online learning experiences. The basic principle is that face-to-face oral communication and online written communication are optimally integrated such that the strengths of each are blended into a unique learning experience congruent with the context and intended educational purpose. Although the concept of blended learning may be intuitively apparent and simple, the practical application is more complex. Blended learning is not an addition that simply builds another expensive educational layer. It represents a restructuring of class contact hours with the goal to enhance engagement and to extend access to Internet-based learning opportunities. Most important, blended learning is a fundamental redesign that transforms the structure of, and approach to, teaching and learning.

The key assumptions of a blended learning design are

- Thoughtfully integrating face-to-face and online learning

- Fundamentally rethinking the course design to optimizestudent engagement

- Restructuring and replacing traditional class contact hours

Blended learning must be approached with the awareness of the broad range of flexible design possibilities and the challenge of doing things differently. It must be based upon a sound understanding of higher-order learning environments, communication characteristics, requirements of various disciplines, and resources. Blended learning redesign is a catalyst; it means to fundamentally reconceptualize and restructure the teaching and learning transaction. Its basic assumption is to open the educational mind to a full range of possibilities. Blended learning brings into consideration a range of options that require revisiting how students learn in deep and meaningful ways. Blended learning is no more about reshaping and enhancing the 
traditional classroom than it is about making e-learning more acceptable. In both contexts one is left with essentially either face-to-face or online learning.

In this paper, blended learning design and practical that should be used in Linear Algebra is taught. This is based on the author's brief study of this course.

\section{Literature Review}

According to Thorne [8] blended learning is the most logical and natural evolution of the learning agenda. This requires an elegant solution to the challenge of tailoring learning and development to individual needs. It is also an opportunity to integrate the innovative advances and technology offered by online learning with the best interaction and participation offered in traditional learning. This can be supported and enhanced by using the personal trainer's discretion and personal contact.

Blended learning is a mixture of:

- multimedia technology;

- Streaming video CD ROMs;

- virtual classrooms;

- voicemail, e-mail and conference calls;

- online text animation and video streaming.

Blended learning is a way to complement face-to-face classes with web-based materials [1]. This learning style is usually defined as the integration of traditional classroom methods with online activities (called "e-learning") [1], [3], [5]. But this blended learning method was developed to complement, not replace, traditional forms of learning [6].

According to [2], the main aspects of teaching and learning are students' own experiences of the process. However, works published on blended learning focus more on different teaching methods and on innovations that are introduced rather than on student experiences [4], [7]

Linear algebra is one of the compulsory subjects in Department of Mathematics, Andalas University. This course has a weight of 4 credits with meetings 2 times a week. This course is also equipped with a tutorial meeting by supporting lecturers. Based on the material in this course, then this subject, according to most students, is one of the subjects in the difficult category. This can be seen from the final grades of students and the number of students who take this course again.

Most of the material in Linear Algebra is theories (ie, theorems, lemmas, propositions and corollaries) which must be proven by various methods of proof in mathematics. Difficulties of students are usually in using the method of proof (steps that must be taken so that the proof is correct). This basically makes it difficult for students to learn the theory themselves. Based on this, lecturers must be careful if they want to give lectures with indirect methods, such as blended learning.

\subsection{Material for Linear Algebra in Blended Learning}

This research was conducted within one semester. Because the researcher wants to see the effect of blended learning in improving student understanding in Linear Algebra, there are two phases of assessment. In the first phase, researchers conducted classroom observations without including blended learning, which is the initial lecture period until midterm; the next phase is 
the end of the midterm to the end of the semester. In this phase the researcher includes blended learning. Following is a rubric table of student responses in the first phase.

Table 1. Student Understanding Level Rubric (Without Blended Learning)

\begin{tabular}{|c|c|c|}
\hline Grade & Score & Indicator \\
\hline Less & $0-5$ & $\begin{array}{l}\text { Students do not understand the theory (do not know } \\
\text { the premise and the part that must be concluded) }\end{array}$ \\
\hline Sufficient & $6-10$ & $\begin{array}{l}\text { Students understand the theory, but cannot write proof } \\
\text { steps, resulting in wrong conclusions }\end{array}$ \\
\hline Good & $11-15$ & $\begin{array}{l}\text { Students understand the theory and students are able to } \\
\text { write the steps, but there is a little wrong placement of } \\
\text { additional theories to reach conclusions }\end{array}$ \\
\hline Very Good & $16-20$ & $\begin{array}{l}\text { Students understand the theory and students are able to } \\
\text { write proof steps correctly until a conclusion is } \\
\text { reached }\end{array}$ \\
\hline
\end{tabular}

Table 2. Student Understanding Level Rubric (With Blended Learning)

\begin{tabular}{|c|c|c|}
\hline Grade & Skor & Indikator \\
\hline Less & $0-6$ & $\begin{array}{l}\text { Students do not understand the theory (do not know the } \\
\text { premise and the part that must be concluded) }\end{array}$ \\
\hline Sufficient & $7-13$ & $\begin{array}{l}\text { Students understand the theory, but cannot write proof } \\
\text { steps, resulting in wrong conclusions }\end{array}$ \\
\hline Good & $14-19$ & $\begin{array}{l}\text { Students understand the theory and students are able to } \\
\text { write the steps, but there is a little wrong placement of } \\
\text { additional theories to reach conclusions }\end{array}$ \\
\hline Very Good & $20-25$ & $\begin{array}{l}\text { Students understand the theory and students are able to } \\
\text { write proof steps correctly until a conclusion is } \\
\text { reached }\end{array}$ \\
\hline
\end{tabular}

The difference in scores on the rubric given for the reasons in Table 1 of pure lectures uses a face-to-face system, whereas in Table 2, there is a combination of face-to-face lectures and blended learning, and there is even material that is given entirely with blended learning.

The design provided in blended learning as is done in general, namely providing lecture material through the media. At this stage the media used is whatsapp group. Researchers form discussion groups by first providing lecture material. The material provided in the form of narration, as well as explaining in class (due to the limitations of researchers, lecture material does not use video).

The following are examples of giving material by researchers:

Lecture Note 4.2. Ortoghonal Bases

Definition 4.2.1

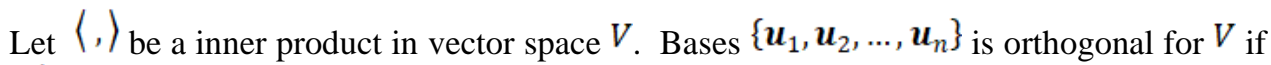
$\left\langle\boldsymbol{u}_{i}, \boldsymbol{u}_{j}\right\rangle=0$ for $i \neq j$.

If each $\left\|\boldsymbol{u}_{i}\right\|=1$ (or each $\boldsymbol{u}_{i}$ is unit vector) then bases $\left\{\boldsymbol{u}_{1}, \boldsymbol{u}_{2}, \ldots, \boldsymbol{u}_{n}\right\}$ orthonormal.

Remark: 
- Definition 4.2.1 states that the orthogonal bases is a base which has a different pair of elements is orthogonal. So suppose that $\left\{\boldsymbol{u}_{1}, \boldsymbol{u}_{2}, \ldots, \boldsymbol{u}_{n}\right\}$ is orthogonal bases in a vector space with inner products, then

- $\left\langle\boldsymbol{u}_{1}, \boldsymbol{u}_{2}\right\rangle=0,\left\langle\boldsymbol{u}_{1}, \boldsymbol{u}_{3}\right\rangle=0,\left\langle\boldsymbol{u}_{1}, \boldsymbol{u}_{4}\right\rangle=0, \ldots,\left\langle\boldsymbol{u}_{1}, \boldsymbol{u}_{n}\right\rangle=0$,

- $\left\langle u_{2}, u_{3}\right\rangle=0,\left\langle u_{2}, u_{4}\right\rangle=0, \ldots,\left\langle u_{2}, u_{n}\right\rangle=0$,

- $\left\langle\boldsymbol{u}_{3}, \boldsymbol{u}_{4}\right\rangle=0, \ldots,\left\langle\boldsymbol{u}_{3}, \boldsymbol{u}_{n}\right\rangle=0$.

- $\left\langle\boldsymbol{u}_{n-1}, \boldsymbol{u}_{n}\right\rangle=0$

- Definition 4.2.1 states that orthonormal bases is orthogonal bases dan for every $\boldsymbol{u}_{n}$, then $\left\|\boldsymbol{u}_{i}\right\|=1, i=1,2, \ldots, n$. So let $\left\{\boldsymbol{u}_{1}, \boldsymbol{u}_{2}, \ldots, \boldsymbol{u}_{n}\right\}$ is orthonormal bases, then

- $\left\langle\boldsymbol{u}_{1}, \boldsymbol{u}_{2}\right\rangle=0,\left\langle\boldsymbol{u}_{1}, \boldsymbol{u}_{3}\right\rangle=0,\left\langle\boldsymbol{u}_{1}, \boldsymbol{u}_{4}\right\rangle=0, \ldots,\left\langle\boldsymbol{u}_{1}, \boldsymbol{u}_{n}\right\rangle=0$

- $\left\langle\boldsymbol{u}_{2}, \boldsymbol{u}_{3}\right\rangle=0,\left\langle\boldsymbol{u}_{2}, \boldsymbol{u}_{4}\right\rangle=0, \ldots,\left\langle\boldsymbol{u}_{2}, \boldsymbol{u}_{n}\right\rangle=0$

- $\left\langle\boldsymbol{u}_{3}, \boldsymbol{u}_{4}\right\rangle=0, \ldots\left\langle\boldsymbol{u}_{3}, \boldsymbol{u}_{n}\right\rangle=0$

$-\quad \vdots$

$-\left\langle\boldsymbol{u}_{n-1}, \boldsymbol{u}_{n}\right\rangle=0$

and

$\left\|\boldsymbol{u}_{1}\right\|=1,\left\|\boldsymbol{u}_{2}\right\|=1,\left\|\boldsymbol{u}_{3}\right\|=1, \ldots,\left\|\boldsymbol{u}_{n}\right\|=1$

- From Definition 4.2.1 we have that orthonormal based is ortogonal, but we cannot always justify if a statement is reversed

Theorem 4.2.2

Let $\boldsymbol{u}_{1}, \boldsymbol{u}_{2}, \ldots, \boldsymbol{u}_{n}$ be an orthonormal bases in a vector space $V$ with inner product $\langle$,$\rangle .$ Then for every $v \in V$,

$\boldsymbol{v}=a_{1} \boldsymbol{u}_{1}+a_{2} \boldsymbol{u}_{2}+\cdots+a_{n} \boldsymbol{u}_{n}$

which $a_{i}=\left\langle v, u_{i}\right\rangle, i=1,2, \ldots, n$.

Proof.

Since $\left\{\boldsymbol{u}_{1}, \boldsymbol{u}_{2}, \cdots, \boldsymbol{u}_{n}\right\}$ is a bases in $V$, then for every $\boldsymbol{v} \in V$, $\boldsymbol{v}=a_{1} \boldsymbol{u}_{1}+a_{2} \boldsymbol{u}_{2}+\cdots+a_{n} \boldsymbol{u}_{n}$. It's shown that $a_{i}=\left\langle\boldsymbol{v}, \boldsymbol{u}_{i}\right\rangle$. Consider that

$<\boldsymbol{v}, \boldsymbol{u}_{i}>=<a_{1} \boldsymbol{u}_{1}+a_{2} \boldsymbol{u}_{2}+\cdots+a_{n} \boldsymbol{u}_{n}, \boldsymbol{u}_{i}>$

$\left.=<a_{1} \boldsymbol{u}_{1}, \boldsymbol{u}_{i}>+<a_{2} \boldsymbol{u}_{2}, \boldsymbol{u}_{i}>+\cdots+<a_{n} \boldsymbol{u}_{n}, \boldsymbol{u}_{i}\right\rangle$

$\left.\left.=a_{1}<\boldsymbol{u}_{1}, \boldsymbol{u}_{i}\right\rangle+a_{2}<\boldsymbol{u}_{2}, \boldsymbol{u}_{i}>+\cdots+a_{n}<\boldsymbol{u}_{n}, \boldsymbol{u}_{i}\right\rangle$

$=a_{1} 0+a_{2} 0+\cdots+a_{i} 1+\cdots+a_{n} 0$

$=a_{i}$

Remark:

- Theorem 4.2.2 states that if $\left\{\boldsymbol{u}_{1}, \boldsymbol{u}_{2}, \ldots, \boldsymbol{u}_{n}\right\}$ is an orthonormal bases in vector space $V \quad$ with inner $\quad$ product, $\quad$ then $a_{i}$ in
$\boldsymbol{v}=a_{1} \boldsymbol{u}_{1}+a_{2} \boldsymbol{u}_{2}+\cdots+a_{n} \boldsymbol{u}_{n}$ can be calculated in a way: $a_{i}=\left\langle\boldsymbol{v}, \boldsymbol{u}_{i}\right\rangle$,
$i=1,2, \ldots, n$, atau $a_{1}=\left\langle\boldsymbol{v}, \boldsymbol{u}_{1}\right\rangle, a_{2}=\left\langle\boldsymbol{v}, \boldsymbol{u}_{2}\right\rangle, a_{3}=\left\langle\boldsymbol{v}, \boldsymbol{u}_{3}\right\rangle, \ldots, a_{n}=\left\langle\boldsymbol{v}, \boldsymbol{u}_{n}\right\rangle$. 
- Review that $a_{i}$ in a arbitrary vector space, can be calculated using this way, that is:

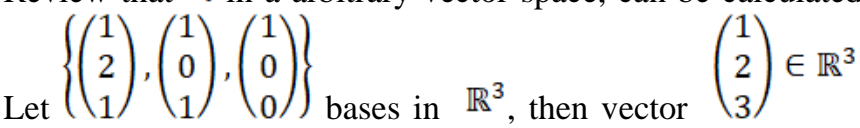
from bases vector, i.e $\left(\begin{array}{l}1 \\ 2 \\ 3\end{array}\right)=a_{1}\left(\begin{array}{l}1 \\ 2 \\ 1\end{array}\right)+a_{2}\left(\begin{array}{l}1 \\ 0 \\ 1\end{array}\right)+a_{3}\left(\begin{array}{l}1 \\ 0 \\ 0\end{array}\right)$. Calculate $a_{1}, a_{2}, a_{3}$ by using elementary row operation.

If bases in vector space is orthogonal, as above, for example
orthogonal bases in $\mathbb{R}^{3}$ with dot product is inner product in $\mathbb{R}^{3}$, then vector $\left(\begin{array}{l}1 \\ 2 \\ 3\end{array}\right) \in \mathbb{R}^{3} \quad$ can be write $\left(\begin{array}{l}1 \\ 2 \\ 3\end{array}\right)=a_{1}\left(\begin{array}{l}0 \\ 1 \\ 0\end{array}\right)+a_{2}\left(\begin{array}{l}1 \\ 0 \\ 1\end{array}\right)+a_{3}\left(\begin{array}{c}1 \\ 0 \\ -1\end{array}\right)$. To calculated $a_{1}, a_{2}, a_{3}$ with two way, that is using elementary row operation and $a_{1}=\left\langle\left(\begin{array}{l}1 \\ 2 \\ 3\end{array}\right),\left(\begin{array}{l}0 \\ 1 \\ 0\end{array}\right)\right), a_{2}=\left\langle\left(\begin{array}{l}1 \\ 2 \\ 3\end{array}\right),\left(\begin{array}{l}1 \\ 0 \\ 1\end{array}\right)\right), a_{3}=\left\langle\left(\begin{array}{l}1 \\ 2 \\ 3\end{array}\right),\left(\begin{array}{c}1 \\ 0 \\ -1\end{array}\right)\right\rangle_{\text {(exercises for you!) }}$

This design is called the author as the design of providing step-by-step information. This lecture material is given to students through whatsapp groups and continued with discussion.

\section{Result and Discussion}

Based on observations to students (44 students), the following results are obtained:

Table 3. Percentages Understanding Student per Topic (Without Blended Learning)

\begin{tabular}{lllllll}
\hline Grade & Score & \multicolumn{5}{c}{ Topic (\%) } \\
\hline & & I & II & III & IV & V \\
Less & $0-5$ & 43 & 5 & 11 & 16 & 59 \\
Sufficient & $6-10$ & 27 & 25 & 16 & 20 & 5 \\
Good & $11-15$ & 7 & 68 & 61 & 16 & 7 \\
Very Good & $16-20$ & 23 & 2 & 11 & 48 & 30 \\
\hline
\end{tabular}

Table 4. Percentages Understanding Student per Topic (With Blended Learning)

\begin{tabular}{llllll}
\hline Grade & Score & \multicolumn{3}{c}{ Topic (\%) } \\
\hline & & I & II & III & IV \\
Less & $0-6$ & 2 & 41 & 45 & 93 \\
Sufficient & $7-13$ & 7 & 23 & 2 & 5 \\
Good & $14-19$ & 23 & 23 & 2 & 0 \\
Very Good & $20-25$ & 14 & 14 & 50 & 2 \\
\hline
\end{tabular}

Based on Tables 3 and 4, it was found that each topic has a different level of understanding by students. It can be seen that the use of blended learning does not have a significant effect on increasing students' understanding.

Next, given the students' final exam scores. 
Table 5. Percentages Final Exam 2018/2019

\begin{tabular}{llcc}
\hline Grade & Score & Number of Student & Percentage \\
\hline A & $80 \leq x \leq 100$ & 5 & 11.36 \\
A- & $75 \leq x<80$ & 4 & 9.09 \\
B+ & $70 \leq x<75$ & 6 & 13.64 \\
B & $65 \leq x<70$ & 9 & 20.45 \\
B- & $60 \leq x<65$ & 7 & 15.91 \\
C+ & $55 \leq x<60$ & 4 & 9.09 \\
C & $50 \leq x<55$ & 3 & 6.82 \\
D & $40 \leq x<50$ & 3 & 6.82 \\
E & $0 \leq x<40$ & 3 & 6.82 \\
\hline
\end{tabular}

Compare with

Table 6. Percentages Final Exam 2017/2018

\begin{tabular}{cccc}
\hline \multicolumn{2}{c}{ Score } & Number of Student & Percentage \\
\hline A & $80 \leq x \leq 100$ & 6 & 13.64 \\
A- & $75 \leq x<80$ & 4 & 11.36 \\
B+ & $70 \leq x<75$ & 3 & 4.55 \\
B & $65 \leq x<70$ & 4 & 9,09 \\
B- & $60 \leq x<65$ & 5 & 11.36 \\
C+ & $55 \leq x<60$ & 7 & 15.91 \\
C & $50 \leq x<55$ & 7 & 15.91 \\
D & $40 \leq x<50$ & 9 & 18.81 \\
E & $0 \leq x<40$ & 0 & 0 \\
\hline
\end{tabular}

\section{Conclusion}

Although blended learning does not have a significant effect on linear algebra but in general, blended learning method can increase student's understanding to Linear Algebra.

Acknowledgments. This work supported by LP3M Andalas University 2019. No. 056/UN.16.18/PT.01.03/2019

\section{References}

[1] Garrison, D. R. \& Kanuka, H. Blended learning: uncovering its transformative potential in higher education. Internet and Higher Education, Vol. 7, No. 2, pp. 95-105 (2004)

[2] Ginns, P. \& Ellis, R. A. Evaluating the quality of e-learning at the degree level in the student experience of blenden learning. British Journal of Educational Tecnology, Vol. 40, No. 4, pp. 652-663 (2009)

[3] Graham, C. R. Blended learning system: definition, current trend, and future direction. Dalam C. J. Bonk \& C. R. Graham (eds), The handbook of blended learning; Global Perpectives, local designs. San Fransisco, CA; Pfeiffer, (2006) 
[4] Lopez-Perez, M. V., Perez-Lopez, M. C. \& Rodrigues_Ariza, L. Blended Learning in higher education: Students' perception and their relation outcomes. Computer \& Education, Vol. 56, pp. 818-826 (2011).

[5] Macdonald, J. Blended learning and online tutoring (2nd ed.) Hampishire, UK: Gower. (2008)

[6] Mitchell, P. \& Forer, P. 2010. Blended learning: the perception of first-years geography student. Journal of Geography in Higher Education, Vol. 34, No. 1, pp. 77-89.

[7] Paetchter, M. \& Maier, B. Online or face-to-face? Student experiences and preferences in e-learning. Internet and Higher Education, Vol. 13, pp. 292-297 (2010).

[8] Thorne, K. Blended Learning: How to Integrate Online and Traditional Learning, Kohan Page Limited, USA. (2003) 